written on stellar spectra is that of Düner on the two types, III $a$. and III $b$. of Vogel's classification. And a study of it will show that no two groups of spectra differ more widely than these.

To secure simplicity I represented the two arms of the temperature curve of equal inclination, and to save space $I$ used a narrow angle between them (although by all analogy the descending arm should fall less rapidly than the ascending one). The more the curve is flattened the less difference there will be in the physical conditions of stars on either side of the apex representing the highest temperature. These stars, therefore, will be difficult to classify, and even some of the conditions may vary in the Alnitamian, Crucian, and Achernian groups.

It is half-way up the two curves that the greatest confusion may arise if stars of the same name; $(A, F, K)$ are treated as if their physical state were similar, $\alpha$ Cygni and Sirius, for ininstance, both $\mathrm{A}$ in the Harvard classification (H.3). NORMAN LOCKYER.

(To be continued.)

THE SERVICE OF SCIENCE.

A

FEW months ago public attention was being directed by articles and letters in the Morning Post to the inadequate remuneration and prospects of scientific workers, particularly those engaged in research. The subject is one to which many columns of NATURE have been devoted since the foundation of this journal in 1869 , but it cannot be too widely discussed if any serious effort is to be made to secure improved conditions in the future. The present is not perhaps the most propitious moment to ask for increased endowment of science and encouragement of discovery, but there are points relating to the position of science which can be stated as appropriately now as at any time. Some of these matters are referred to in an article on "Science and the State" in the October number of Science Progress, and the whole subject is under consideration by a committee of the British Science Guild.

The article in Science Progress is in continuation of one which was published in the April number, and its purpose is to offer a programme of steps toward the betterment of science in Britain and elsewhere. It is shown that the emoluments of scientific men are much below what might reasonably be expected for exceptional attainments; and the claim is made that the State should offer special rewards or pensions to investigators whose researches have proved of decided national or public advantage without being profitable to themselves.

The unsatisfactory positions of many professors and lecturers in our universities and other institutions of higher education, is due largely to the management of the institutions by commercial men who like to see fine buildings but are unable to understand the use of most of the work carried on in them. It comes as a surprise to such men to be told that in scientific circles usefulness is rarely adopted as the standard of value; and that even if. not a single practical result is reached by an investigation, the work is worth doing if it enlarges knowledge. or increases our outlook upon the universe. This proposition, of course, leaves the practical man cold; yet it is all that science desires to offer in justification of its activities. While the discovery of truth remains its single aim, science is free to pursue inquiries in whatever direction it pleases; but when it permits itself to be dominated by the spirit of productive application it will become merely the galley-slave of short-sighted commerce. Almost all the investigations upon which modern industry has been built would have been crushed at the outset if immediate practical value had determined what work should be undertaken. Science brings back new seeds from the regions it explores, and they seem to be nothing but trivial curiosities to the people who look for profit from research, yet from these seeds come the mighty trees under which civilised man has his tent, while from the fruit he gains comfort and riches.

Industrial research is concerned, not with the discovery of truth, but with the production of something which will be of direct service to man and from which pecuniary profit may be secured: it is the province of the inventor rather than that of the man of science. Such research and that carried on with no ulterior motive are complementary to one another. Science has done its part when it has made a new discovery; constructive engineering renders good service when it shows how the discovery may be chained to the advancing chariot of industry. To foresee the possibilities of a discovery, to transform a laboratory experiment into the mechanical plant of a large works, or to apply it to the needs of ordinary life, require aptitudes not commonly possessed by the scientific investigator. The engineer usually has such practical purposes in mind; discoveries are to him things to be used and not ends in themselves, as they are to the man of science. He seeks not so much to know Nature as to circumvent her; and the research which he undertakes or organises has for its object the artificial preparation of substances which are naturally rare, the production of a new process or the improvement of an old, the design of machines which will increase his power over her, and of instruments which will enable him to laugh at limitations of time and space.

Research is necessary for these advances, but the spirit in which it is carried on is essentially different from that of the scientific worker. The engineer or the inventor first of all perceives a need and then endeavours to devise a means of meeting it. If he is of a scientific type of mind he will make an accurate analysis of the conditions to be fulfilled, and then design his machine or instrument to fulfil them; but the usual way is to find practically what will perform the required functions, and to leave experience or scientific knowledge to indicate how improvements may be effected.

$$
\text { NO. } 235 \text { O, VOL. 94] }
$$


Scientific research may thus be divided conveniently into two classes-one in which the motive is solely the desire to extend the boundaries of knowledge, while in the other the special purpose is to obtain results which have a direct bearing upon problems of manufacture and construction. Explorers on the ship of science go out to discover new lands; and their spirit is not the same as that which actuates the prospectors who follow them with the intention of making the lands profitable to themselves and others. Both these classes of pioneers have their proper places in the scheme of progress, but they live in different atmospheres. The scientific investigator must have freedom to follow his own course wherever it may lead, whereas technical research can be organised and definite problems presented for which solutions of direct service to man are sought. The standard of value in one case is that of knowledge only, while in the other it is that of profit or use. The scientific mind desires to understand Nature; the engineering mind to control her for material purposes.

Some time ago the votes of the readers of an American periodical-Popular Mechanics-were taken as to what inventions were considered to be the "seven wonders of the modern world." From a list of numerous inventions, seven had to be selected; and those which received the highest number of votes were: wireless telegraphy, the telephone, the aeroplane, radium, antiseptics and antitoxins, spectrum analysis, and X-rays. Each one of these things had its foundations in purely scientific work, and was not the result of deliberate intention to make something of service to humanity.

It would be easy to give many further instances of the foundation of great industries upon results obtained in scientific investigation. Credit is, of course, due to the engineers who convert laboratory experiments into commercial undertakings, and to inventors for making use of scientific results in the production of instruments and devices for the convenience and comfort of man; but in both cases they are adapters of new knowledge rather than creators of it. The new field is opened by the man of science, but he is usually forgotten by those who afterwards take possession of it.

National well-being can only be secured when the close relation between it and scientific progress is understood. Discoveries which lead directly to developments of industry and manufacture may almost be left to take care of themselves, and the search for them is not likely to be neglected, but it is not.the case with those for which no immediate use can be seen, yet almost all scientific research comes within that category. This is the kind of research which needs encouragement more than any other, and demands the greatest amount of originality, inspiration, and enthusiasm, to produce apparently insignificant results. The man who has zeal for work of this kind, who is a born researcher, should be cherished by his country above all others, and

$$
\text { NO. } 2350 \text {, VOL. 94] }
$$

every advantage be offered him for the pursuit of knowledge.

When men of science ask for funds for scientific research they do not wish to bury the talents they receive or to derive personal profit from them. Whatever amount is entrusted to them is returned a hundredfold in the results achieved. How many are the researches worthy of assistance, and how small are the funds available for investigations having no obvious practical application, are understood only by men of science themselves. It would be a revelation to people endowed with a larger share of worldly riches to be present at a meeting of the committee of the British Association concerned with the allocation of grants for scientific purposes. Thirty or forty of the leading men of science in the British Isles discuss for several hours how to divide the sum of about roool. which represents the amount available from the sale of tickets at each annual meeting. There are many applications for grants from committees of each of the twelve sections of the Association, and the amount required has usually to be whittled down to $5 l$. or rol., which often does not cover the expense of stationery and postage of a research committee. Not one penny goes into the pockets of the men who are conducting the researches, yet claim after claim has to be passed, or reduced to its lowest limits, because the fund is miserably inadequate to meet the demands made upon it.

The Royal Society was unable to find the money required to print Newton's "Principia," and it was published at the expense of his friend. Halley. Our scientific societies are in no better position to-day. Their members-most of whom possess but very slender means-pay by their own subscriptions for the publication of the results of their investigations. They sacrifice their leisure, and draw upon their limited resources, not only that knowledge may be increased, but also that the gain may be published to the world, which is free to make use of it.

It is difficult for the man of the world to understand the altruistic spirit which induces men of science to band themselves together in societies having for their sole aim the advancement of knowledge in particular directions; and that these men should themselves pay to enlighten and benefit others by the publication of their researches is almost incomprehensible to the selfish or money. making mind; yet such is the case. While the annual State grant made by Great Britain towards the expense of the publications of learned societies is limited to the sum of one thousand pounds to the Royal Society, several times that amount is provided each year for stationery alone used by members of the House of Commons.

The politicians who pay themselves a salary for the time they devote to party tactics and personal persiflage would be astounded if the proposal were made to provide for the support of Fellows of the Royal Society or of any other scientific institution, yet of the relative values to the nation of the work done in the two spheres of politics and 
science, there can be no question. In a splendid building and surrounded with all the appurtenances of precedent and dignity, months and years are wasted in a game of finding weak points in arguments relating to subjects many of which are of doubtful national importance; while the scientific elect of the country are crowded in modest apartments to discuss discoveries which it has cost them much time and frequently much money to complete, and for the publication of which they must themselves make provision. It requires the satire of a Swift to describe the disparity of support afforded to polemics and natural philosophy by a State that owes most of its modern advance to scientific work.

There is no doubt that the greatest contributions to knowledge have been made by men who undertook their inquiries into Nature without thought of proximate or ultimate practical application or pecuniary reward. It is true also that the best kind of scientific investigation cannot be carried on in an atmosphere of commercialism, or where personal profit is the end in view. This, however, does not relieve the nation of the responsibility for seeing that the rare aptitude for original research receives the most generous encouragement. At present a scientific career is the last into which a man should enter who expects a reasonable reward for his knowledge and industry; for it is the least lucrative of all professions. The reason is that its members do not form a corporate professional body to secure for science the position which it should hold in the thought and affairs of the State; therefore, administrators and officials generally pay little attention to its claims. Scientific men should see that fuller national recognition is given to their work, and the programme in Science Progress will show some of the directions in which they may well effect improvements, so that the world shall recognise "the great principle that of all forms of human effort, those efforts which result directly in discovery, whether in science or in art, are by far the most important efforts for humanity."

R. A. Gregory.

\section{EXPLORATIONS ON THE NORTH-EAST FRONTIER OF INDIA.}

$A$ MONGST the many activities of the Indian $A$ Survey Department not the least in scientific interest is the series of exploratory surveys which have been carried out on the north-east frontier, to the north and east of Assam, in the wild and mountainous hinterland which lies between Tibet and Burma. The scientific interest of these explorations is two-fold, geographical and ethnographical. The region dealt with in the report of Colonel Sir Sidney Burrard (Surveyor-General of India) embraces the principal basins of the rivers Mekong, Salween, and Irrawaddy and the Himalayan catchment areas of the four principal feeders of the Brahmaputra, namely, the Lohit (Zayul), the Dibang, the Diháng, and the Sabansiri, and for the sheer physical difficulties

$$
\text { NO. } 235 \text { O, VOL. 94] }
$$

offered to systematic mapping is probably unmatched by any equal area in the world.

The scantiness of population, denseness of jungle, altitude of ranges, steep precipices, torrential streams and infernal climate have so far practically barred communication between India and China and between Tibet and Burma. It is here that four survey detachments have been working intermittently from I9I I to 1914 to assist each other in cracking that old geographical nut which lay enshrined in the mountains which overhang the course of the Brahmaputra and the sources of the Irrawaddy. We have heard of the remarkable exploits of geographers, such as Caplain Bailey, who traversed those regions with unexampled success and vindicated the reputation of earlier native explorers, but we have not heard much of the determined efforts of the official pioneers of scientific mapping, whose work furnishes the basis of all successful explorations.

The scientific interest of work accomplished in the field of geography is naturally great and varied, for it is comprised in a large field of 28,000 square miles of hitherto unknown and unmapped mountains. Perhaps the chief point which calls for recognition is the discovery of a gigantic snow peak (Namcha Barwa), 25,445 ft. in altitude, far to the east of Kinchinjunga. The discovery of a peak in Assam nearly as high as Nanda Devi $(25,645 \mathrm{ft}$.) "marks an epoch," says Col. Burrard, "in the history of Himalayan explorations," and the further fact that the Brahmaputra cuts its passage across the Himalayas at the base of this mountain gives rise to a curious problem in mountain hydrography; for it is noteworthy that the Sutlej, the Indus, and the great river of Hunza all cut through main ranges close to the points of supreme elevation of those ranges. Is this only a coincidence, or are we to seek for a reason in the processes of construction of mountain chains?

Another interesting matter is the absence of falls in the Brahmaputra. This is a feature common to most, if not all, of the great Himalayan rivers which descend rapidly from great altitudes to the plains. There are, indeed, magnificent cascades throughout the Himalayas, and a tremendous drop is not uncommon at the point where a tributary joins its parent river, but there are no falls in the main streams.

As for the ethnographical interest of the regions under review, it is so extensive and embraces such a variety of problems that it is only possible to point out generally that here, if anywhere, are we to find the modern representatives of the very oldest of primeval Asiatic races. We are content to generalise under such terms as Tibeto-Burman, or Indo-Chinese, a vast aggregation of tribespeople who differ so widely in their social idiosyncrasies, and even in anthropological features, that there must almost certainly be amongst them survivals who can help point the way to the very beginning of the human alphabet in Asia. All information that can be obtained about them, about their physical conditions, their habitat, 